wound with the handles of the artery forceps sticking out. He then told us that in a few days he would start and remove the artery forceps one by one over a period of several days. We were all horrified that this emaciated young man, when blood transfusion was not available, was subjected to this ordeal. Of course we never saw the final result. On returning to Britain I described this operation over a few years to various colleagues and it was extraordinary that three or four of them told me that they had seen the same operation, so presumably this was one of this surgeon's show pieces, which he did on each occasion.

\section{Prostatectomy under local anaesthesia}

This was the first and only time that I had ever seen a prostatectomy done entirely under local anaesthesia. The patient lay on the table, the bladder was fully distended with water, the abdominal wall was infiltrated with a local anaesthetic, and an incision was made into the bladder, the edges of which were firmly retained. A finger was then put into the base of the bladder to act as a guide for a very long needle, directing the point of the needle, we hoped, to the space between the prostate gland and its capsule. The needle was reinserted some eight or nine times, circling round the upper surface of the prostate gland. After a few minutes digital removal of the prostate gland on a very cooperative patient was carried out. A tube was put in the bladder to complete the operation. It seemed to me a method of making an easy operation a very difficult one indeed.

\section{Cadaver}

In my second week when I went back to my dead body I found that the previous week's body had been removed and a new cadaver of a different sex was now waiting for me. I had recently been a demonstrator in anatomy and knew how rare bodies were, so I went to the professor and explained that I had only paid $£ 30$ for this course and in no way could I expect a second body. He smiled blandly and then told me that these bodies came from Russia in truck loads by train, and looking at them I thought that this was probably true. I could hardly believe this because I had qualified shortly after the first world war when bodies were very scarce and students were very numerous; in fact, I think in the dissecting room in our universities at that time as many as 24 students would be working on one bodynaturally not all at one time. I rang up our anatomy department recently to find out the current position, and apparently seven students to one body is about average. So many people now donate their bodies to the department that there is no longer a shortage.

At the end of the course we had a photograph taken of the group, which I still possess; also, for a few francs one could buy a photograph of any professor. I still have the one of Professor Legeu, signed with his kindest regards.

\title{
Paintings of a nineteenth century operating theatre
}

\author{
Denis Gibbs, Jonathan Evans
}

Until the closing years of the nineteenth century even the largest general hospitals needed only a single operating theatre. Sir Frederick Treves (1853-1923) recalled his early experience at the London Hospital when "one operating theatre was sufficient for a hospital of 700-800 beds, and only one day a week was required." It was considered a sensible use of the accommodation for the theatre to double as a lecture and demonstration room. Though general anaesthesia was used widely by the middle of the century and Lister's first publication on antisepsis appeared in 1867 , these developments had little immediate impact on the number of operations performed in hospital. Surgical activity, however, increased rapidly towards the end of the century. The surgery beadle, who kept a register of operations at the London Hospital, listed a two and a half fold increase between 1887 and $1891 .^{2}$

The old operating theatre at the London Hospital was built in the late eighteenth century and continued in use virtually throughout the nineteenth century. It was situated in the top storey of the front of the hospital beneath a large skylight to catch all the daylight available from the sky above London's east end. Gas light gave supplementary illumination. The theatre had a much longer existence than the oldest surviving operating theatre in Britain, that in the former St Thomas's Hospital, Southwark, but the designs of the two theatres were very similar. When St Thomas's Hospital was rebuilt in Lambeth in 1860 and the main building in Southwark demolished in 1862 to make way for the railway near London Bridge Station the operating theatre, which had been constructed in the roof space of St Thomas's church, then the hospital's chapel, was sealed off and forgotten for nearly a century. It was rediscovered in the 1950 s and subse-

Royal London Hospital Archives and Museum London E1 2AA Denis Gibbs, consulting physician

Jonathan Evans, archivist

Correspondence to: Mr Evans.

BMF 1992;305: 1549-50

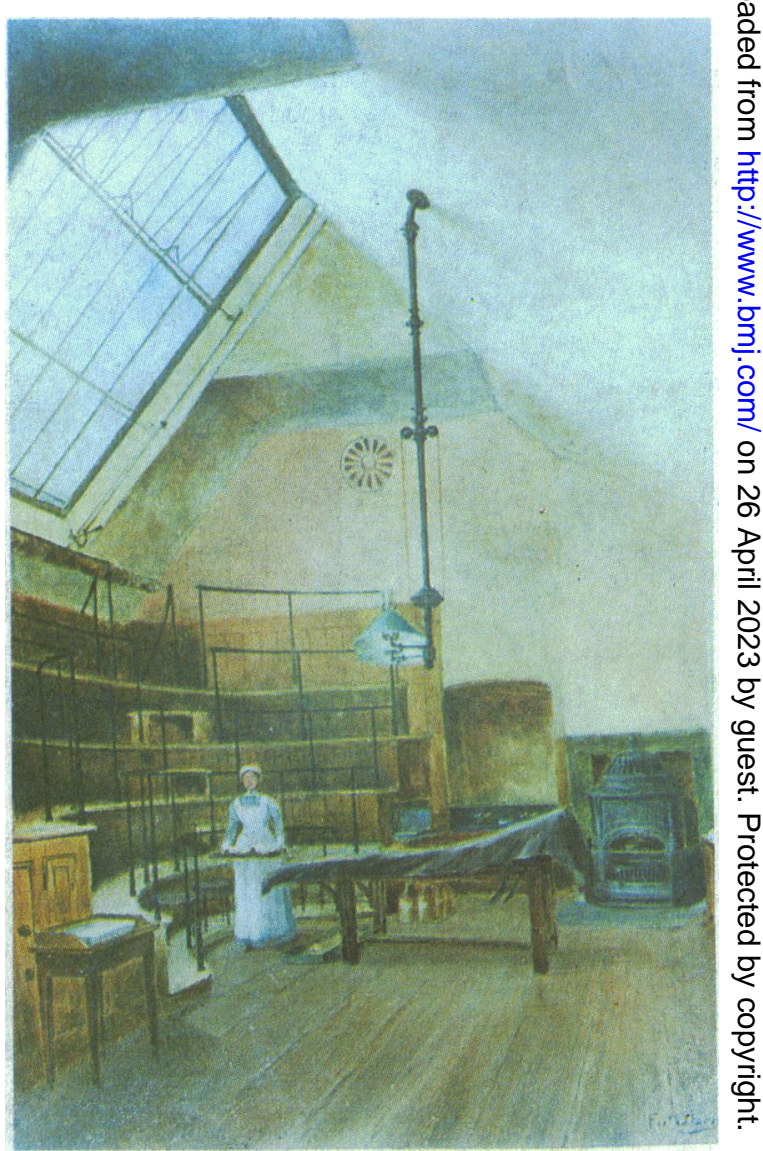

The old operating theatre as it appeared shortly before it was demolished in 1896. The large skylight caught all available daylight and the fire was never allowed to go out 
an important part of London's medical heritage. Interior details shown in two paintings of the theatre at the London Hospital (figures) helped in the accurate restoration of St Thomas's Hospital's old theatre, which now belongs to the Special Trustees of Guy's Hospital.

The guide book for visitors to the operating theatre museum includes several contemporary descriptions of similar theatres as well as some reference to surgical practice in such theatres. ${ }^{3}$ For the old theatre at the London Hospital a comparable personal reminiscence is available from Wilfred Grenfell (1865-1940), who recounted his student days at the London Hospital in his autobiography.

There rises in memory the picture of [a senior surgeon] removing a leg at the thigh, clad in a blood-stained, black velvet coat, and without any attempt at or idea of asepsis. The main thing was speed, although the patient was under ether, and in quickly turning round the tip of the sword-like amputation knife, he made a gash in the patient's other leg. The whole thing seemed horrible enough to us students, but the surgeon smiled saying, "Fortunately it is of no importance, gentlemen. The man will not live." The day came when everyone worked under clouds of carbolic steam which fizzed and spouted from large brass boilers over everything; and then the time when every one was criticizing the new, young surgeon, Treves, who was daring to discard it, and getting as good results by scrupulous cleanliness. His aphorism was "Gentlemen, the secret of surgery is the nailbrush.""

No individual surgeons at the hospital could match the theatre experience of the surgery beadle, a veritable factotum. For a span of 30 years Josiah Rampley held this office at the London Hospital. His duties included running the theatre and charge of all instruments, attendance at surgeons' rounds, and day and night responsibilities in the receiving room. At the time he started he combined these duties with the position of porter and assistant in the postmortem room: such was the accepted scene in pre-Listerian times. Rampley recounted that staff went straight from the postmortem room to theatre, washed their hands or not as they liked, and then donned ancient frock coats that had stood the test of many years' service. This practice

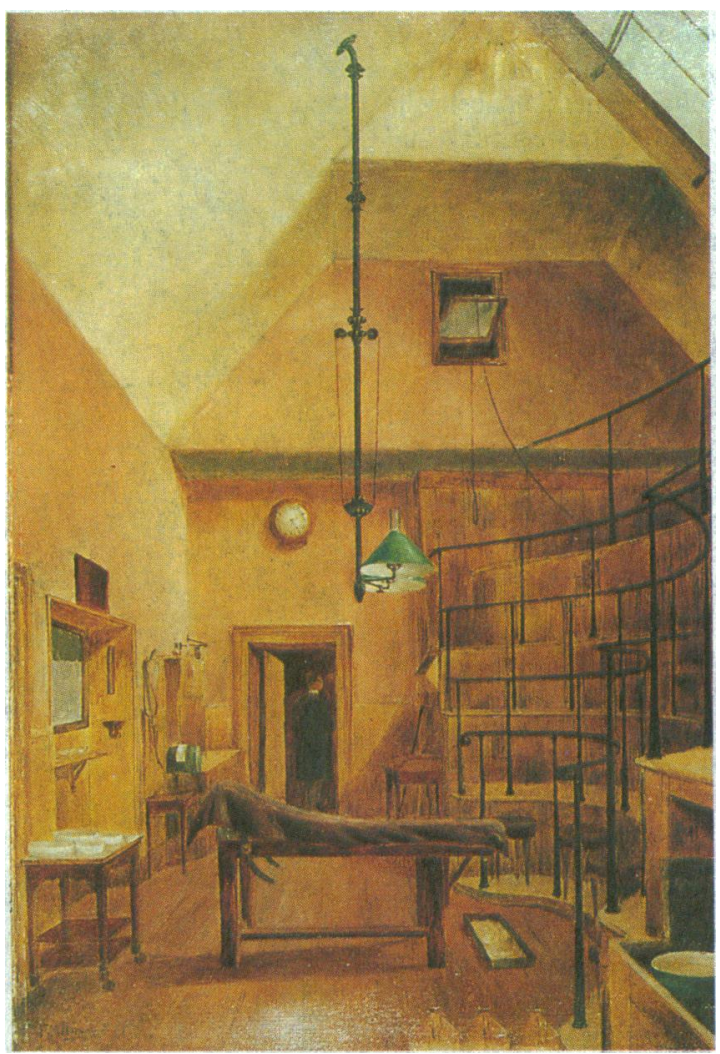

stopped after Rampley had been in post about two years, and some years later Treves persuaded the house committee to change the duties further and reduce the hours of the surgery beadle. Even for those with long memories for times past, Rampley's duties before the reforms seem scarcely credible. He was on duty from $730 \mathrm{am}$ until $11 \mathrm{pm}$ and then on call at night to attend operations; he was allowed alternate Sundays off. The house committee minutes record that "his various works are continuously overlapping and pressing one on the other, so that he is hardly able to get his meals except by taking them in a picnic fashion in the receiving room." Rampley remained a most loyal servant of the hospital, and he and Treves were firm friends.

Jonathan Hutchinson $\mathrm{Jr}$, whose appointment as a surgeon on the staff overlapped that of his famous father, Sir Jonathan Hutchinson, wrote an article on the old and the new operating theatres at the London Hospital. ${ }^{6}$ One of the most important improvements in the new developments had been the introduction of an anaesthetising room. Hutchinson recalled that "in the old times the patient was carried in on a stretcher, and plunged down on the table in the full view of the seried rows of onlookers, or very often he walked in wrapping his blanket about him in the manner of the patriarchs. What an ordeal it must have been thus to enter directly into the scene of the drama in which he made his first and unrehearsed appearance." He went on to describe various features of the old theatre and past surgical practice.

The operating table itself was of the most solid and simple construction, and of fabulous age. ... The lower end of the table was provided with two leather slippers, into one of which the patient's foot would be placed in an amputation of the opposite limb. The old tin of sawdust is shown in the picture and these were indeed the days of gory operations, before the elastic tourniquet was introduced, or the Spencer Wells forceps were dreamt of. Hot irons were used to sear the vessels with before the silk ligatures came into vogue, and were employed frequently at the same time as the latter. All the ligatures were expected to come away, and were, therefore, left long, those on the main arteries being distinguished by their extra length or size. Hence, after an amputation, the dresser's notes to the effect that "the patient is doing well, much laudable discharge" or "the wound gapes in a satisfactory manner, smell not very offensive" were varied about the end of a week or ten days by the record of the fall of the ligatures, with or without secondary haemorrhage. ${ }^{6}$

Treves too referred to the fire, which was "never allowed to go out in the operating theatre since a red hot iron might, at any time, be needed to arrest bleeding."

Treves possessed a keen sense of history and occasion, ${ }^{7}$ and it was entirely in character for him to commission an artist to paint accurate representations of the old theatre before it was demolished in $\mathbf{1 8 9 6 .}$ Later he presented the two small oil paintings to the hospital, where they are now preserved in their original frames in the Royal London Hospital Archives and Museum. They are rare and possibly unique portrayals in colour of such a theatre. The paintings are signed by the artist, F M Harvey. Further information concerning the artist has so far not been discovered and would be much welcomed.

1 Treves F. A tribute to a great woman. London Hospital Gazaette 1919;22:223-4. 2 Surgery beadle's return of operations performed 1887-1891. Royal London Hospital archives $L H / M / 3 / 8-10$

The operating theatre of the United Borough Hospitals of Guy's and S Thomas'. Ashford and London: Headley, [1980].

4 Grenfell W. A Labrador doctor. The autobiography of Wilfred Thomason Grenfell. London: Hodder and Stoughton, 1920.

House Committee minutes, 6 June 1886. Royal London Hospital archives LH/A/5/42.

6 Hutchinson J. The old and the new operating theatres at the London Hospital. London Hospital Gazette 1897;2:4-7.

7 Gibbs DD. Sir Frederick Treves: surgeon, author and medical historian. fR Soc Med 1992;85:565-9. theatre; the artist, FM Harvey, was commissioned by $S$ ir

Frederick Treves. Note the gas lighting and sawdust box 